\title{
Multi Carrier PWM based Multi Level Inverter for High Power Application
}

\author{
Ms.T.Prathiba. Ph.D \\ Thiagarajar College of Engineering \\ Madurai, Tamil nadu \\ India
}

\author{
Dr.P.Renuga \\ Thiagarajar College of Engineering \\ Madurai, Tamil nadu \\ India
}

\begin{abstract}
A new scheme of Multi Carrier Pulse Width Modulation (MCPWM) method for the control of a three-level inverter is proposed. Multi Carrier Pulse Width Modulation (MCPWM) works with a constant carrier frequency not synchronized with fundamental stator frequency. MCPWM gives an optimal utilization of switching frequency permitted, therefore PWM carrier frequency may be chosen to a value of two times the permitted switching frequency. Many applications of three-level inverters work with a dc-link neutral point not stabilized from the power input converter. A flying capacitor multi level inverter is described, which is capable of stabilizing potential by varying the switching sequences of the three-level inverter itself. Results from MATLAB simulation show the good performance of MCPWM.
\end{abstract}

\section{Keywords:}

Multi level inverter, Multi carrier PWM

\section{INTRODUCTION}

Appeared in the early 70's in different fields of applications, multilevel inverters represent a high potential for realization of high power controllable conversion systems of different nature, rectifiers, inverters, high power amplifiers, etc.[1],[2],[3]. The series connection of large turn-off devices in the $\mathrm{kV}$ range is a serious and not a solved problem because of the dispersion of turn-off time from one device to another. Even with emerging technologies and progress in the devices themselves, in the snubber technology and also the gate control, the technology of direct series connection will certainly be limited to a low number of devices. Alternative solution is to connect in series several controllable cells on the base of single device connection, to get a multilevel source.

\section{MULTI LEVEL INVERTER}

Multilevel PWM inverters, including three-level ones, have significant advantages over conventional one because of the capability of operating the motor with nearly sinusoidal current waveforms and higher output voltages. Consequently, interest in actual applications is increasing. In discussing practical applications, still larger capacity inverters are also anticipated, such as those for large ac motor drives. In order to increase the capacity of an inverter, connection in parallel is an effective method. In general, a multilevel inverter could also be obtained by connecting the inverters in parallel with different phases for the carriers, and certain techniques and control methods should be considered when doing this. In high-power applications for instance, the carriers should be synchronized to the modulating sinusoidal waves. In addition, each three phase waveform should be built in quarter-wave symmetry as well as half-wave symmetry.

In this paper, Multi Carrier Pulse Width Modulation (MCPWM) should be preserved. To improve the harmonic characteristic of three phase multilevel inverters, a few modulation strategies have been designed and are discussed.

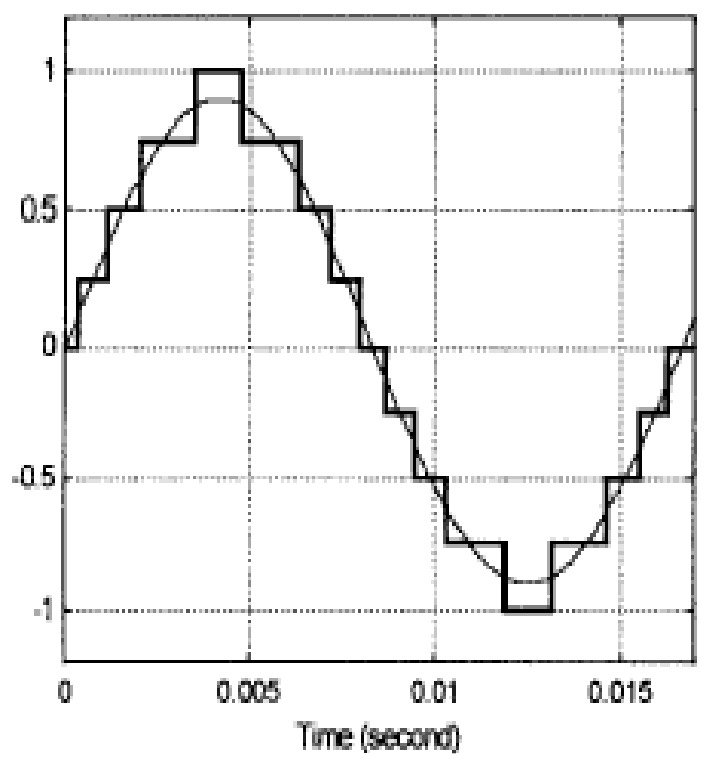

Fig.1. A.typical output waveform of a stepped multilevel modulation for sinusoidal input. 


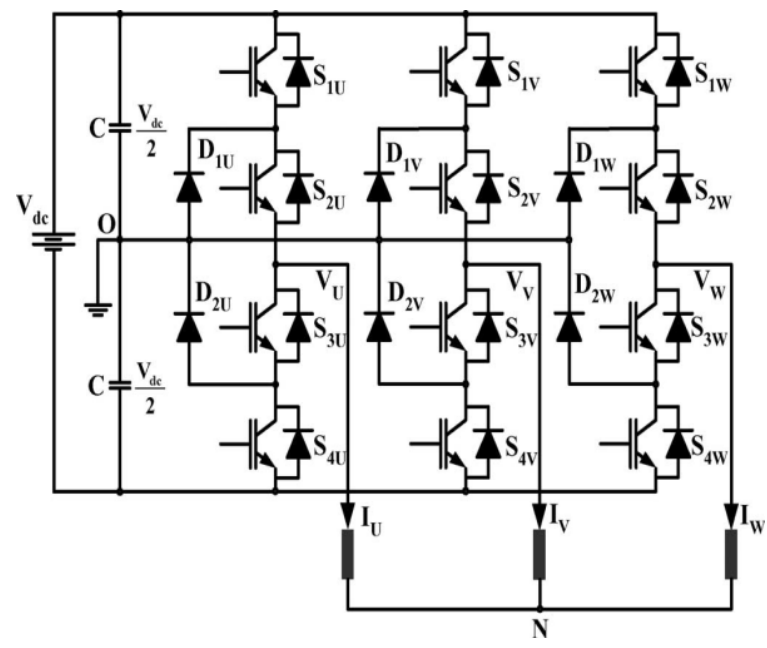

Fig.2.Three level neutral point clamped inverter

Fig.3 Shows a per phase diagram of Five-level PWM inverter, with a capacitor-clamped topology, used to achieve high power and DC bus voltage regulation.

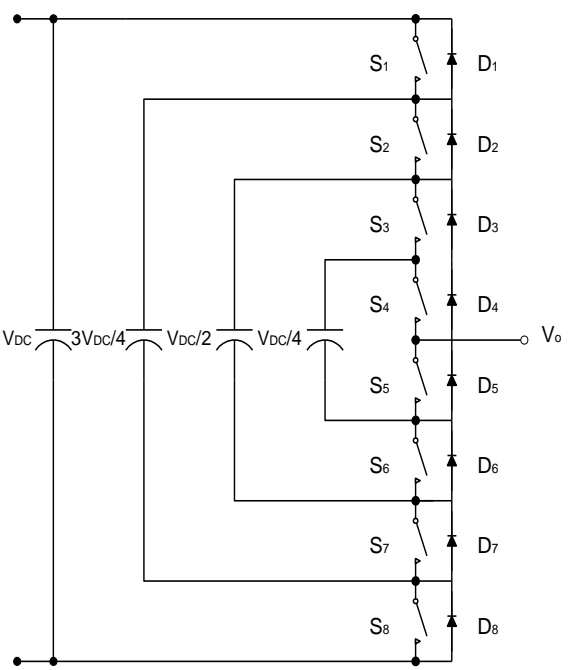

Fig.3 Capacitor clamped multi level inverter

\section{MULTI CARRIER PWM}

Having more than two voltage levels to build a sinusoidal shape it is intuitive that we can have reduction of the current harmonics in the load. Nevertheless, the actual improvement of the current spectrum depends on the control technique employed.

The most popular control technique for traditional inverters is the sinusoidal or "subharmonic" natural pulsewidth modulation (PWM) method. Its popularity is due to its simplicity and to the good results it guarantees in all the operating conditions, including "overmodulation," which allows first harmonic.

A complete analysis of both bipolar (for two-level inverters) and unipolar (for three-level inverters) methods has been widely. We now develop a analysis of the MCPWM method for multilevel inverters. We refer to the system outlined in Fig. 4,

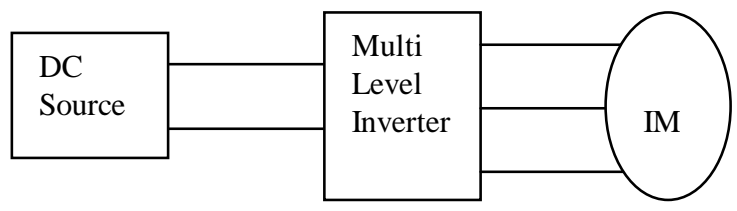

Fig.4. Block Diagram of Multi level inverter

For the proposed multilevel generalization of the PWM method, we take as a starting point the unipolar technique. The idea we follow is to use several triangular carrier signals, keeping only one modulating sinusoidal signal. If an $\mathrm{N}$-level inverter is employed, $\mathrm{N}$ - 1 carriers will be needed.

The carriers have the same frequency $w c$, and the same peak-topeak amplitude $A c$ and are disposed so that the bands they occupy are continuous (see Fig. 5)

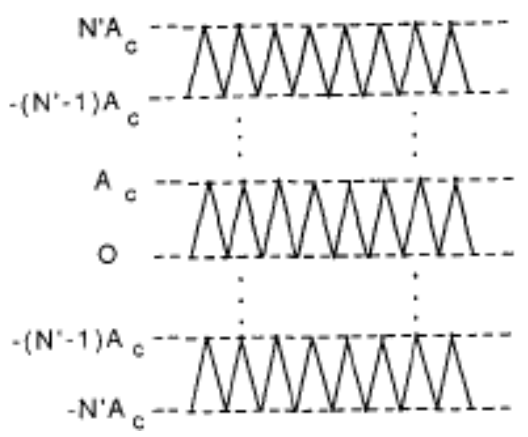

Fig.5. Carrier Disposition

where

$$
N^{\prime}=(N-1) / 2
$$

The zero reference is placed in the middle of the carrier set. The modulating signal is a sinusoid of frequency $w_{m}$ and amplitude $A_{m}$. At every instant each carrier is compared with the modulating signal. Each comparison gives 1 (-1) if the modulating sinusoid is greater than (lower than) the triangular carrier in the first (second) half of the fundamental period, 0 otherwise. The results are added to give the voltage level, which is required at the output terminal of the inverter. Obviously, the actual driving signals for the power devices depend on the particular structure chosen to realize the inverter and thus can be derived from the results of the modulating-carriers comparison by means of a simple logic circuit.

In the case of three-phase inverters we can choose between two different ways in which the switching waveforms of the three 
legs are produced. To comply with the requirements for a threephase system, we need always three 120" phase-shifted modulating sinusoids. The two possibilities are distinguished by the use of the carrier signals.

First, a single carrier set may be used to be compared with the three modulating sinusoids (single-phase modulation). Second, three different carrier sets with 120" phase displacement among themselves may be used, each to be compared with the corresponding sinusoid (three phase modulation).

An analysis of the two possibilities for a bipolar modulation is given in [7]. The results apply directly to the multilevel modulation, showing the superiority of the single-phase modulation. This is because in this case the harmonics at multiples of $w c$, which are always of high amplitude, are cophasal and so are not present in the spectra of the load phase voltages and of the load phase currents. Thus, in the following we consider only single-phase modulation.

The zero reference is placed in the middle of the carrier set. The modulating signal is a sinusoid of frequency $w_{m}$ and amplitude $A_{m}$. At every instant each carrier is compared with the modulating signal. Each comparison gives 1 (-1) if the modulating sinusoid is greater than (lower than) the triangular carrier in the first (second) half of the fundamental period, 0 otherwise. The results are added to give the voltage level, which is required at the output terminal of the inverter. Obviously, the actual driving signals for the power devices depend on the particular structure chosen to realize the inverter and thus can be derived from the results of the modulating-carriers comparison by means of a simple logic circuit.

In the case of three-phase inverters we can choose between two different ways in which the switching waveforms of the three legs are produced. To comply with the requirements for a threephase system, we need always three 120" phase-shifted modulating sinusoids. The two possibilities are distinguished by the use of the carrier signals.

First, a single carrier set may be used to be compared with the three modulating sinusoids (single-phase modulation). Second, three different carrier sets with 120" phase displacement among themselves may be used, each to be compared with the corresponding sinusoid (three phase modulation).

An analysis of the two possibilities for a bipolar modulation is given in [7]. The results apply directly to the multilevel modulation, showing the superiority of the single-phase modulation. This is because in this case the harmonics at multiples of $w c$, which are always of high amplitude, are co phasal and so are not present in the spectra of the load phase voltages and of the load phase currents.

Thus, in the following we consider only single-phase modulation.
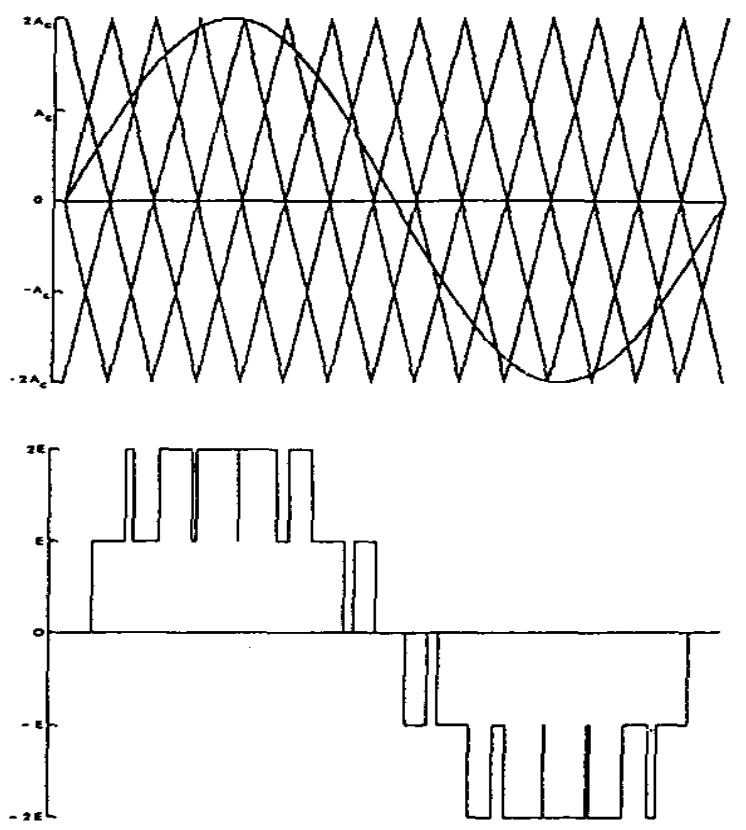

(a)
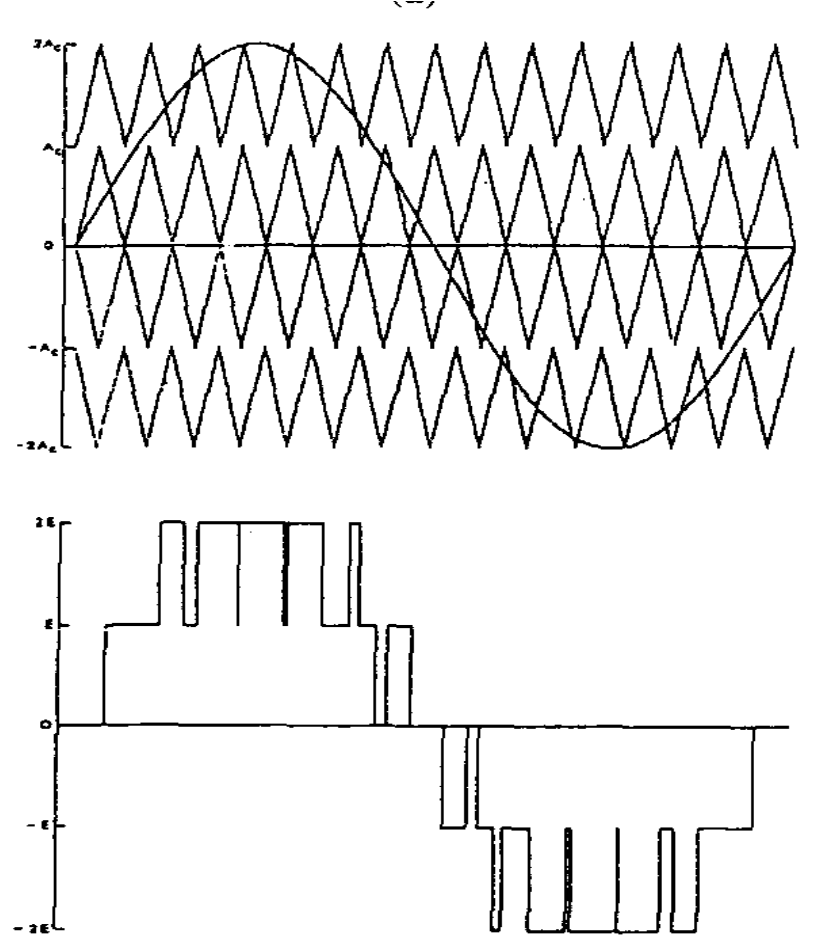

(b) 

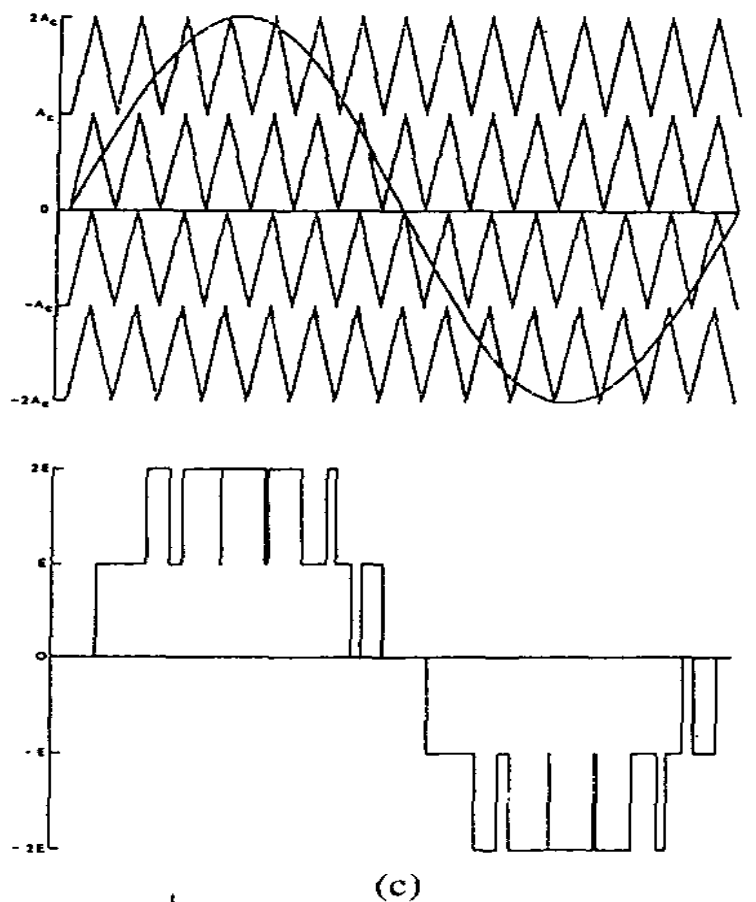

Fig.6. Three Techniques of MCPWM

\section{SWITCHING STRATEGY}

The general case of a multilevel inverter with different partial voltages are defined by fig. 5 . One inverter half-leg is realized with the elements connected in series, $T_{1}, T \sim . ., T_{n}$, which have each their own antiparrallel diode $\mathrm{D}_{1}, \mathrm{D}_{2}, \ldots \mathrm{Dn}$,. The example of the known three-level inverter is used.

With such an inverter scheme, the leg voltage which is defined between the output point and the negative bar of the DC link, can take $\mathrm{N}_{\mathrm{b}}$ different values , according: $\mathrm{N}_{\mathrm{b}}=\mathrm{n}+\mathrm{l}$ (b-branch).

This $\mathrm{N}_{\mathrm{b}}$-number defines the usual number of possible levels, that is compatible with the example of the known three-level inverter.
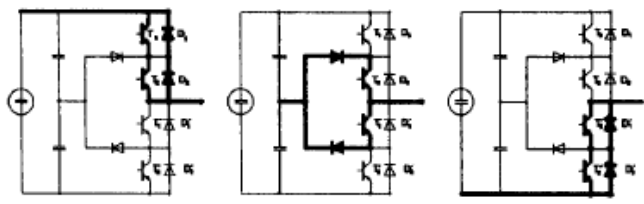

Fig. 7. Three-level inverter leg multilevel inverter switching scheme is to ensure that the switches operate in the contiguous modes. The most popular and simple methods are step modulation and sinusoid pulse width modulation (SPWM).

In SPWM, four triangular signals are compared with the sinusoid reference signal to get the switching control signal. These triangular signals are contiguous and have the same peak-to-peak value.

According to different phase relationship, there are three cases: a). all triangular signals are in phase; b). the two contiguous triangular are out of phase; and c). the positive triangular signals are in phase and the negative triangular signals are in phase, but the positive and the negative are out of phase. The proposed PWM method has been verified by the computer simulations.

Table1.Switching Strategy

\begin{tabular}{|l|l|l|l|l|l|l|l|l|}
\hline Output & S1 & S2 & S3 & S4 & S5 & S6 & S7 & S8 \\
\hline Vdc & 1 & 1 & 0 & 0 & 0 & 0 & 1 & 1 \\
\hline Vdc/2 & 1 & 0 & 0 & 1 & 0 & 0 & 1 & 1 \\
\hline 0 & 0 & 0 & 1 & 1 & 0 & 0 & 1 & 1 \\
\hline- Vdc/2 & 0 & 0 & 1 & 1 & 1 & 0 & 0 & 1 \\
\hline- Vdc & 0 & 0 & 1 & 1 & 1 & 1 & 0 & 0 \\
\hline
\end{tabular}

\section{SIMULATION RESULTS}

The feasibility of the proposed PWM strategy has been investigated and verified through computer simulation results for the Three level inverter system as shown in Fig.6.

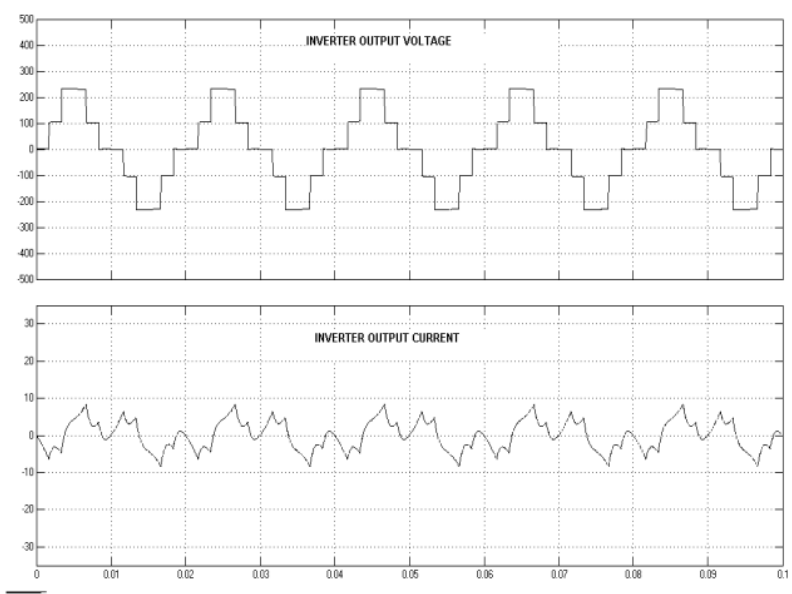

Fig.8. (a) Inverter phase voltage (b) Invrter phase current 


\section{CONCLUSION}

In this paper, a novel voltage modulation strategy for the three level voltage source converter based on a multi carrier PWM has been proposed. The proposed method is so simple that it can be implemented even with a few analog circuits. The feasibility of the proposed PWM method has been verified by the computer simulations results. As a conclusion, the use of a multilevel inverter proves to be very interesting under the aspect of reducing the harmonic contents.

\section{ACKNOWLEDGMENTS}

The authors thank the Management, the Principal \& EEE Department of Thiagarajar College of Engineering for providing the necessary facilities to carry out this work.

\section{REFERENCES}

[1] W. Schminke, High-Power Pulse-Step Modulator for $500 \mathrm{~kW}$ Short-Wave and 600kW Medium-Wave Transmitters, Brown Boveri Rev. 72 (1985) (5) 235-240
[2] B. Gotas, B. Knaf€l, P. Knapp, A. Rufer, Stromrichterschaltung und Verfahren $z u$ dessen Steuerung Europilische Patentschrift 025491 1 B 106.07 .87

[3] A. Nabae, I. Takahashi, H. A@, A New Neutral-PointClamped PWM Inverter EEE Trans. On Ind. Appl. Vol IA 17 No5, pp. 518-523 (1981)

[4] A.-Ch. Rufer An aid in the teaching of multilevel inverters for high power applications 7803-2730-6195 @ 1995 IEEE

[5] Ying Cheng Mariesa L. Crow A Diode-Clamped Multi-level Inverter For the StatCom/BESS 0-7803-7322-7/02/ (C) 2002 IEEE

[6] Jang-Hwan Kim, A Carrier-Based PWM Method for ThreePhase Four-Leg Voltage Source Converters IEEE transactions on power electronics, vol. 19, no. 1, january 2004

[7] Giuseppe Carrara, Simone Gardella, Mario Marchesoni, A New Multilevel PWM Method: A Theoretical Analysis IEEE transactions on power electronics, vol. 7, no. 3, july 1992 